\title{
Characterization of Additive Manufacturing for Process Tubing
}

\author{
PAUL S. KORINKO $₫,{ }^{1,4}$ JOHN T. BOBBITT III, ${ }^{1}$ MICHAEL J. MORGAN ${ }^{1}$ \\ MARISSA REIGEL,${ }^{1}$ FREDRICK A. LIST III, ${ }^{2}$ and \\ SUDARSANAM SURESH BABU ${ }^{3}$
}

\begin{abstract}
1.-Savannah River National Laboratory, Aiken, SC, USA. 2.-Oak Ridge National Laboratory, Manufacturing Develop Facility, Oak Ridge, TN, USA. 3.-University of Tennessee-Knoxville, Knoxville, TN, USA. 4.-e-mail: paul.korinko@srnl.doe.gov
\end{abstract}

\begin{abstract}
Additive manufacturing (AM) is being considered as a primary manufacturing process for heat pipes. The Savannah River National Laboratory is researching AM to fabricate a hydrogen isotope separation unit for a thermal cycling absorption process that cycles from cryogenic to moderate temperatures and is a pressure boundary. AM is being explored as a replacement technology to improve heat transfer. Simple test samples with three internal geometries were designed and built from type 316L stainless steel using the powder bed fusion laser process. Nine test article geometries were prepared and subjected to tensile and burst testing and were interrogated using $\mathrm{x}$-ray computed tomography and metallography. The parameters selected for processing the tubes produced a consistent product with acceptable tensile properties and microstructures; however, the process parameters used did not produce full density and minor modifications are needed to achieve full density.
\end{abstract}

\begin{tabular}{ll} 
AM & \multicolumn{1}{c}{ Abbreviations } \\
CAD & Compitive manufacturing \\
CT & Computed tomography \\
DT & Dual tube \\
EDM & Electrical discharge machining \\
FT & Finned tube \\
GTAW & Gas tungsten arc welding \\
MDF & Manufacturing demonstration facility \\
ORNL & Oak Ridge National Laboratory \\
PBF-L & Powder bed fusion-laser \\
SEM & Scanning electron microscopy \\
SRNL & Savannah River National Laboratory \\
SS & Stainless steel \\
ST & Single tube \\
TCAP & Thermal cycling absorption process
\end{tabular}

\section{INTRODUCTION}

Freeform fabrication, additive manufacturing, and three-dimensional printing all describe a common process that produces new materials from starting stock that can be metal, plastic, or ceramic. The heat sources typically used include electron beams and lasers. Many reviews describe these processes in detail. ${ }^{1-3}$ The laser processes can use directed energy and powder injection into the molten pool or a powder bed process. The directed energy systems can build on existing components or be used for repair, ${ }^{4,5}$ while the powder bed systems require a build plate and are not amenable to repair processes but can be used for component manufacturing.

In powder bed fusion-laser (PBF-L) processing, a computer-aided design (CAD) drawing from the designer is sliced into sections for machine control and downloaded to the control computer. Proprietary software is then used to control the laser operations to fabricate the part. ${ }^{6}$ The duration of the build depends on the size and number of the components on the build plate. The parts can then either be used or tested depending on the purpose of the build. While there is currently a significant level of effort to define what testing is required for acceptance, with the Holy Grail being "born qualified", 7 that ideal has not yet been achieved, and part qualification is commonly used. The goal is to have the science and engineering well understood prior to making parts to minimize or eliminate destructive testing. However, to achieve this ideal, preliminary work must be accomplished to better understand limitations, material reproducibility, and design criteria. 
For this project, thermal cycling absorption process (TCAP) tubing was selected as an exemplar. The TCAP equipment has historically been fabricated from annealed austenitic (types 304L or 316L) stainless steel for thermal, hydrogen compatibility, and fire safety requirements. TCAP is used to purify hydrogen isotopes, $\mathrm{H},{ }^{2} \mathrm{H}$, and ${ }^{3} \mathrm{H}$ (protium, deuterium, and tritium) using palladium on keiselghur. TCAP works similarly to gas chromatography. Palladium has a higher chemical affinity for the lighter isotopes, and when the system is thermally cycled, the lighter elements are bound more tightly to the $\mathrm{Pd}$ than the heavier ones. Therefore, as the temperature and pressure are reversed, the heavy isotopes travel further than the light ones and isotopic separation occurs. By cycling the temperature and adding gas, a high-purity product (99.99\%) can be achieved along with a high-purity raffinate. The capacity of the TCAP is determined by the diameter of the piping and the rate at which the temperature can be cycled from -40 to $140^{\circ} \mathrm{C}$. Several generations of TCAP have been fabricated, tested, and in some cases deployed; the effectiveness of the TCAP is related to the number of stages present, which can be loosely translated as the length of the process piping. The current state-ofthe-art TCAP is a "ying-yang" design fabricated out of austenitic stainless steel, either type 304L or type $316 \mathrm{~L}$, that is brazed with cooling coils and process gas coils and uses a heater cartridge. It has a pipe length of $6 \mathrm{~m}^{8-11}$ The brazing process introduces several defects that reduce the efficiency and may result in scrap formation. Braze defects between the layers create air gaps and cause a reduction in the heat transfer coefficient compared with conduction from the solid tubing or braze.

TCAP elements with a number of different designs were considered for heat transfer, basic property development, and fabricability. Three internal geometries were selected, and a total of nine pipe-like segments were built from type 316L stainless steel using a Renishaw AM250 PBF-L system; this process selection is not unique, and fabrication of heat pipes using AM has been considered by others. ${ }^{12}$ PBF-L was chosen for this research project because of its ability to produce stainless steel components with finer details than the blown powder directed energy deposition (DED), although DED is also compatible with readily available type $316 \mathrm{~L}$ stainless steel powder and has reasonably well-known processing parameters. ${ }^{13-15}$ To ensure that the tubes had the highest tensile strength so that minimum wall thickness could be used to reduce the thermal mass, the tubes were tested in the as-printed condition. The yield strength of the tubes was considered more important than ductility; simple heat treatment has been shown to improve ductility presumably by reducing dislocations while hot isostatic pressing can heal porosity and reduce the dislocation density, which decreases yield strength. ${ }^{16}$ The test samples

fabricated for this effort were inspected, burst tested, cut into test specimens, and evaluated for mechanical and microstructural features in the asfabricated condition.

\section{EXPERIMENTAL APPROACH}

Specimens were designed to test the features of interest for the TCAP. These designs included a simple single tube (ST) to replicate $9.5-\mathrm{mm}$ stainless steel tubing, a dual tube (DT) with thermowells, and a finned tube (FT) sample with heater strip ports, thermowells, and fins that are intended to enhance the heat transfer between the working and process fluids. The original designs were modified to improve the fabricability. ${ }^{6}$

All nine parts were built in a single build using the Renishaw AM250 PBF-L system, with the parts arranged to minimize the potential for rake interference during fabrication. The build parameters are listed in Table I and do not include contour passes, which can be used to improve surfaces. Relatively large hatch spacing was used to shorten the build time, and both virgin and recycled powders were used. The powder hopper was permitted to automatically fill during processing.

Samples were visually examined while attached to the build plate and after electrical discharge machined (EDM) removal from the plate.

Computed tomography (CT) was conducted on all nine samples in the as-received condition using a voxel size of $\sim 120 \mu \mathrm{m}$ : the large voxel size was chosen to enable short scan times for the whole tube sample and to look for gross defects. The tubes were examined in two sections so the entire sample was computer tomographed. Selected samples were examined after burst testing using a voxel size of $34 \mu \mathrm{m}$ to better visualize any defects.

High-pressure tube fittings were gas tungsten arc welded (GTAW) onto the components; for multiplechambered tubes, only one section was selectively burst tested. The samples were burst tested using a hybrid hydraulic-gas test method in which the tubes were initially filled with water and then pressurized with gas until failure. A high-pressure gas volume

Table I. Renishaw AM250 SLM build parameters used to produce the TCAP process tubes

\section{Powder}

Powder size

Laser power

Layer thickness

Scan pattern

Beam size

Point distance

Point exposure

Effective velocity

Hatch spacing
Renishaw 316L SS

$15-45 \mu \mathrm{m}$

$200 \mathrm{~W}$

$50 \mu \mathrm{m}$

Meander

$75 \mu \mathrm{m}$

$50 \mu \mathrm{m}$

$90 \mu \mathrm{s}$

$0.56 \mathrm{~m} / \mathrm{s}$ $150 \mu \mathrm{m}$ 
was used to manually control the pressurization rate and to minimize the pressure excursions during testing; the pressure and time data were logged using LabView-based data acquisition software. The tests were conducted in an engineered test cell, and pressurization was done remotely; the pressurization rate was manually controlled by a valve.

Sub-size tensile samples $(25 \mathrm{~mm}$ long with a 12 $\mathrm{mm}$ reduced gauge at $1.5 \mathrm{~mm}$ width by the build thickness) were electrical discharge machined from the components. These tensile test samples were then tested to failure in tension on an Instron 4507 load frame with an MTS ReNew control package. The testing used a cross-head speed of $0.13 \mathrm{~mm} / \mathrm{min}$ $(0.005 \mathrm{ipm})$. An extensometer with a gauge length of $7.6 \mathrm{~mm}$ (0.3 in.) was used to measure the strain.

The fracture surfaces were examined using a Hitachi S3000 scanning electron microscope with an accelerating voltage of $25 \mathrm{kV}$. The samples were examined at magnifications from 100 to $1000 \times$.

Metallographic samples were also electrical discharge machined from the tubes. The samples were cut so tube sections could be examined in the axial and transverse orientations. The samples were mounted in epoxy, ground, polished, and then electrolytically etched with $10 \%$ oxalic acid. The samples were examined on a reflected light microscope with photos taken at magnifications from 50 to $500 \times$.

\section{RESULTS AND DISCUSSION}

The three-dimensional rendering of the firstgeneration tube types is shown in Fig. $1 \mathrm{a}$ and $\mathrm{b}$; these tubes had $90^{\circ}$ overhangs and no ports for powder removal. Modifications to the original designs are shown in Fig. 1c and d. These modifications addressed the shortcomings of the initial designs by removing the $90^{\circ}$ overhangs and reducing them to $<45^{\circ}$ to reduce the melt through and improve the printability. In addition, the top end of the tube segment was open to enable the loose powder to be removed.

The samples were arranged on the base plate to enable each part to be completed without causing other parts to be adversely affected if the system were to experience a process upset. This can be seen in Fig. 1e, which shows the successful printing of nine TCAP elements on the baseplate. The samples were built over the course of about $45 \mathrm{~h}$, as indicated in the data log shown in Fig. 1f. It took 4194 layers to build these tube segments at approximately $50 \mu \mathrm{m}$ per layer. These tubes were wire electrical discharge machined from the plate. The samples appear uniform in color and exhibit the expected metallic gray color. The surfaces exhibited the expected surface roughness but did not show visual defects. The data $\log$ in Fig. If shows a stable chamber temperature with time, cyclic pressure, and a disruption in the oxygen content after about $23 \mathrm{~h}$; this point will be discussed later.
The samples had been effectively cleaned at Oak Ridge National Laboratory (ORNL) Manufacturing Development Facility (MDF). There was no evidence of loose powder either on the external surface of the components or in the internal cavities, as indicated by $\mathrm{x}$-ray computed tomography (CT) inspection. However, the surfaces were rougher than expected, in part due to the lack of contour passes, but the surface particles are consistent with other researcher's work. ${ }^{17}$

All the samples were examined using low-resolution CT. The scans did not reveal any major defects. The scans did clearly show that there were some attached particles on the internal surfaces, but the tubes were not filled with powder. The resolution was about $120 \mu \mathrm{m}$, and no pores were detected at this resolution.

High-pressure tubes were manually gas tungsten arc welded onto one of the powder removal ports on one sample of each internal configuration. The pretest condition of the bulkhead near the weld is shown in Fig. 2a. As can be seen, there was a significant amount of discoloration after welding. The welder indicated that the AM samples offgassed and were more challenging to weld than wrought material; this situation is likely caused by the rough surfaces due to the absence of contour layers.

The pressure versus time test data for the three samples are shown in Fig. $2 \mathrm{~b}$. The pressurization slope is indicative only of the testing method and was controlled by manually adjusting the control valve between the test sample and the standard volume. Using thin-wall pressure vessel calculations (Eq. 1):

$$
\sigma=p * r / t
$$

where $\sigma$ is the hoop stress, $p$ is the pressure, $r$ is the tube radius, and $t$ is the tube thickness. Equation 1 provides the calculated ultimate tensile strengths indicated on the chart as well as in Table II. The measured wall thicknesses are also noted in Table II; for the finned tube, both the outer and inner diameters and thicknesses are listed. Note that the reported UTSs are higher for ST and DT samples than the FT sample even compared with the actual wall thicknesses and diameters. Further examination of the FT sample was conducted and is reported later in this article.

The appearance of the burst-tested samples is shown in Fig. 2c. These images exhibit several conditions of note. The first is that all three samples failed in the upper third of the build. In general, one would expect failure to occur near the center of the tube since that is the location for the maximum stress. The single tube failed in such a way as to fully separate while the double tube opened up with "butterfly wings". The finned tube exhibited an internal failure and bulging. In addition, a circumferential crack is visible on the external surface. 


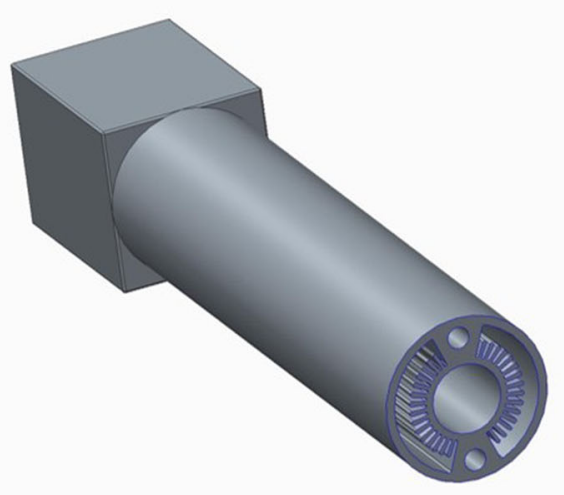

(a)

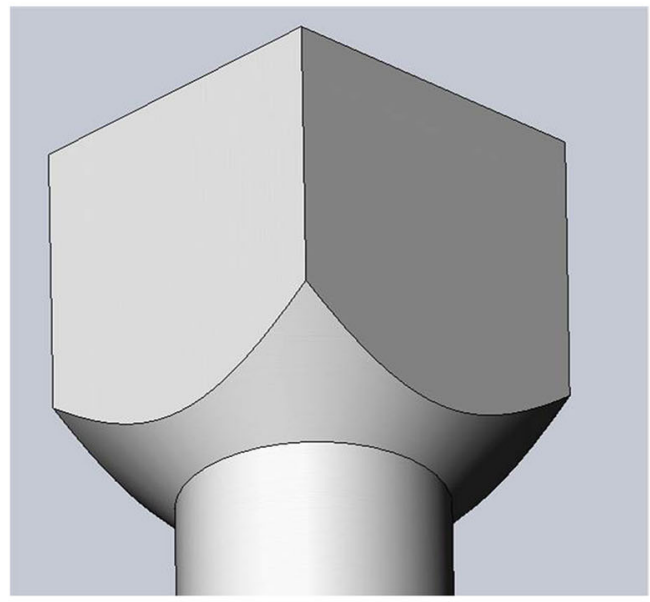

(c)

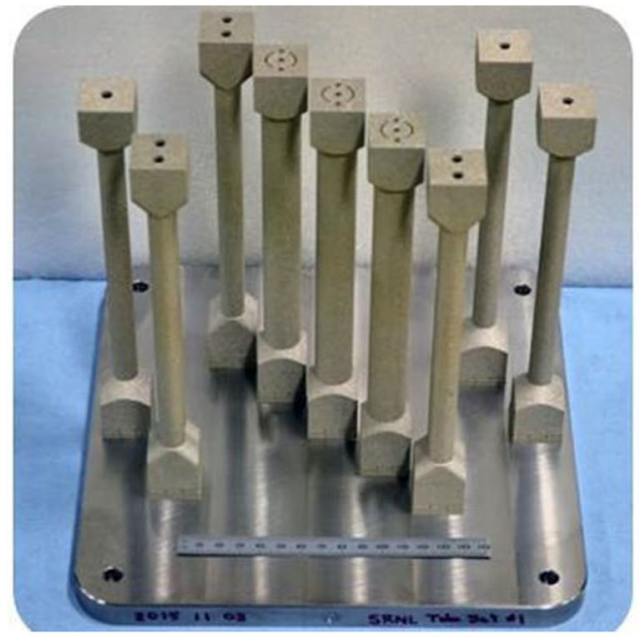

(e)

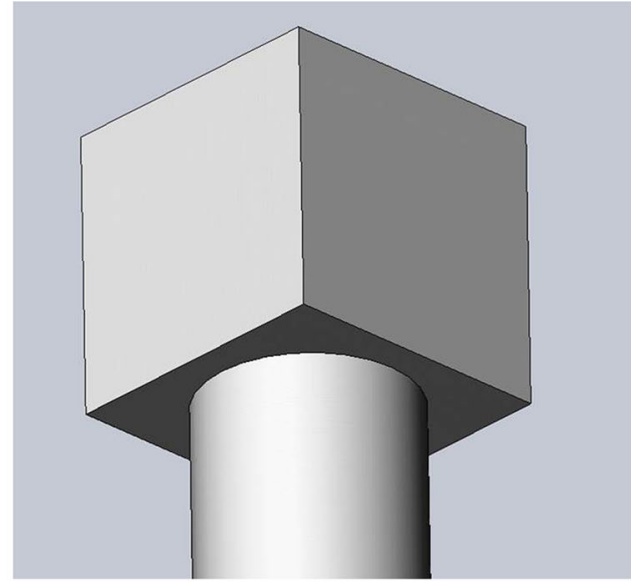

(b)

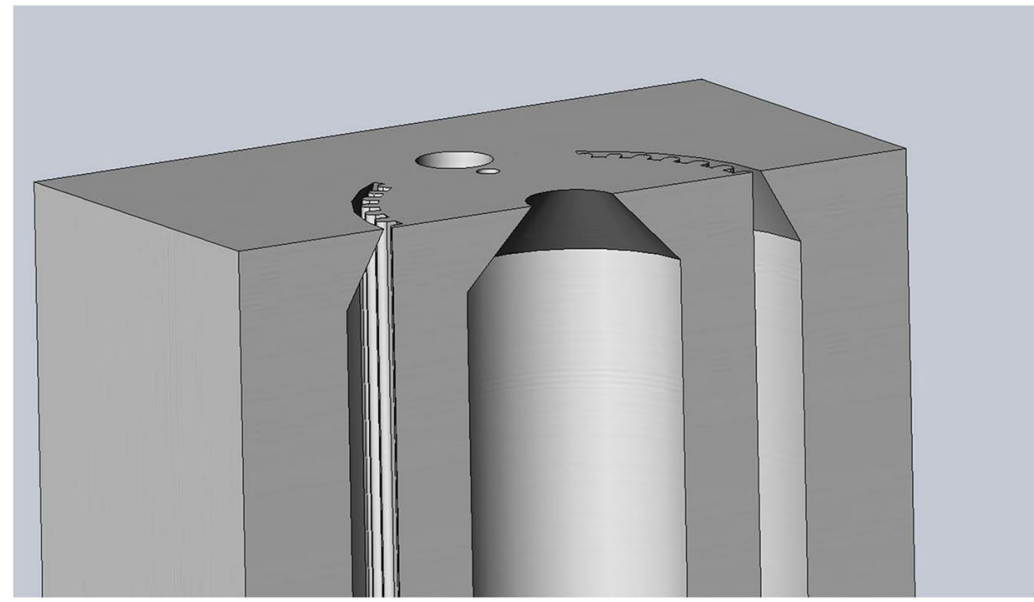

(d)

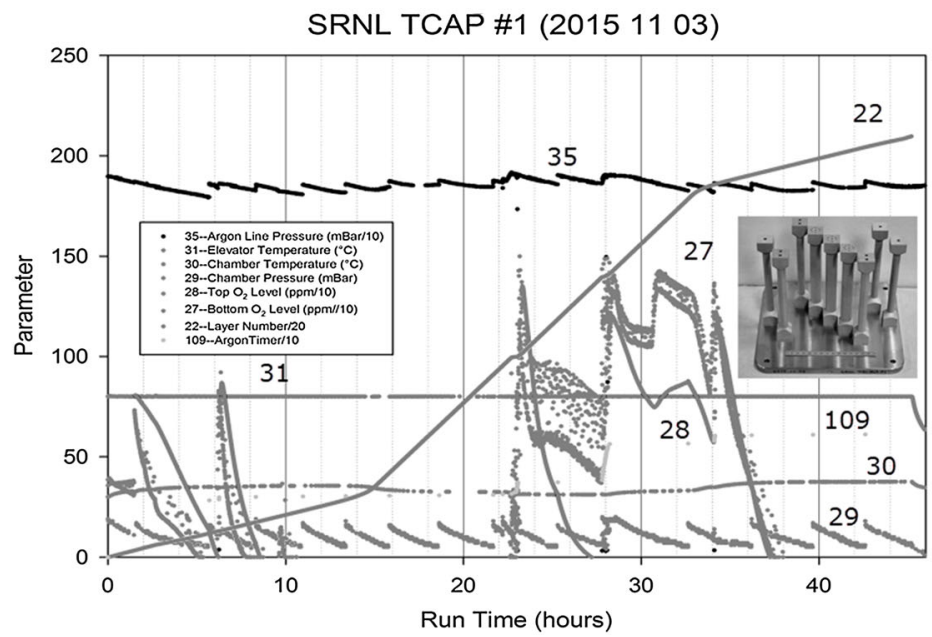

(f)

Fig. 1. (a) Initial design of a finned tube (FT) element showing the internal geometry and the bulkhead connector and (b) the top of the single tube. (c) Improvements suggested by the MDF staff to improve the chances for a successful build of the TCAP elements by changing the overhang angles (d) incorporating powder release holes. (e) Actual layout of the built TCAP elements on the baseplate with offsets to prevent the powder blades from crossing each other, and (f) Renishaw log data showing the pressure, temperature, and oxygen content as a function of time for the 40-h build with a processing upset at around $23 \mathrm{~h}$ and extending for $14 \mathrm{~h}$. 


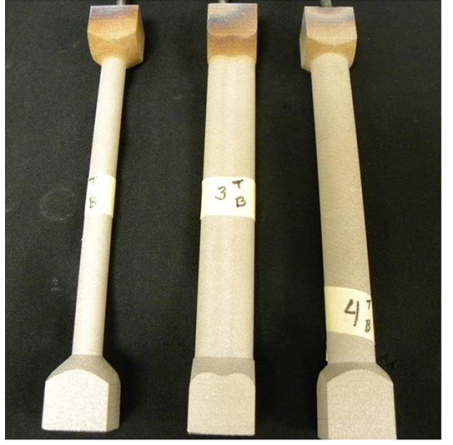

(a)

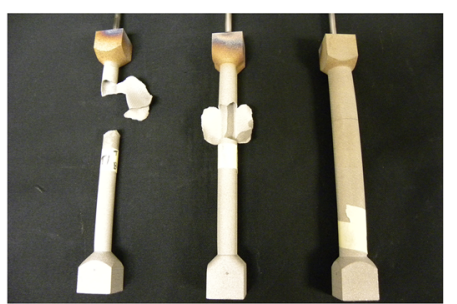

(c)

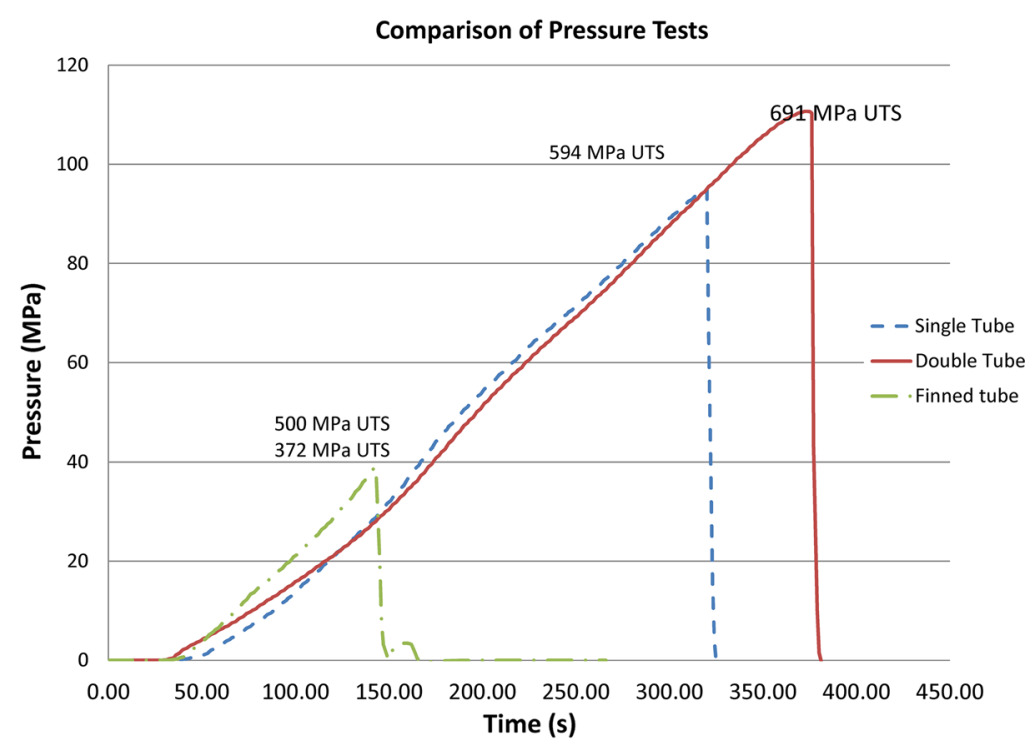

(b)

Fig. 2. (a) Condition of the burst test samples after welding but prior to burst testing; the welded area shows the expected heat tint as well as some smoking. (b) Burst test pressurization results for the single tube (ST), double tube (DT), and finned tube (FT) shown in (c) and (c) post-burst test condition of the AM process tube.

Table II. Burst test results and mechanical properties test data from the tubes

\begin{tabular}{|c|c|c|c|c|c|c|c|c|c|}
\hline Sample & $\begin{array}{l}\text { Radius } \\
\text { mm (in) } \\
\end{array}$ & $\begin{array}{c}\text { Wall } \\
\text { mm (in) }\end{array}$ & $\begin{array}{l}\text { Pressure } \\
\text { MPa (ksi) } \\
\end{array}$ & $\begin{array}{c}\text { “UTS" stress } \\
\text { MPa (ksi) } \\
\end{array}$ & $\begin{array}{c}\text { YS MPa } \\
(\mathbf{k s i}) \\
\end{array}$ & $\begin{array}{c}\text { UTS MPs } \\
\text { (ksi) } \\
\end{array}$ & $\begin{array}{c}\% \\
\text { Elong } \\
\end{array}$ & $\begin{array}{l}\text { RA } \\
(\%) \\
\end{array}$ & $\begin{array}{c}\text { Hardening } \\
\text { slope }\end{array}$ \\
\hline Single & $9.5(0.375)$ & $0.93(0.036)$ & $110(13.7)$ & $594(86)$ & $387(56.2)$ & $487(70.7)$ & 27.6 & 27.0 & 3.4 \\
\hline $\begin{array}{l}\text { Dual } \\
\text { Finned }\end{array}$ & $9.5(0.375)$ & $0.99(0.039)$ & $93(16.0)$ & $691(100)$ & $425(61.6)$ & $498(72.3)$ & 18.8 & 34.9 & 3.4 \\
\hline $\begin{array}{l}\text { OD } \\
\text { ID }\end{array}$ & $\begin{array}{l}9.5(0.375) \\
5^{*}(0.200)\end{array}$ & $\begin{array}{l}0.74(0.029) \\
0.52(0.021)\end{array}$ & $40(5.6)$ & $\begin{array}{l}500(73) \\
372(54)\end{array}$ & 391 (56.7) & $469(68.0)$ & 30.1 & 28.7 & 3.6 \\
\hline
\end{tabular}

*Represents a minimum burst pressure.

The persistent failure location associated with the process upset was unique relative to other burst testing that has been conducted for PBF-L fabricated type 316L SS; in these samples, the burst failures occurred at various positions over the length of the specimens. ${ }^{18}$ These tube segments were prepared using the same Rensishaw AM250 as was used for the current study, but no process upsets occurred during these builds. It appears that the persistent failure location is associated specifically with this process upset. While no specific damage mechanism can be ascribed to the burst location, a detailed microchemical assessment was completed: The results are inconclusive based on the methodology used. ${ }^{19}$

Since this failure location and mode, i.e., splitting with circumferential tearing, were unexpected, an additional review of the process data was conducted.
The laser power and other data are consistent across the run, but an anomaly was observed in the oxygen data, as mentioned previously. There was an increase in the oxygen content at about $2 / 3$ of the build time, as shown in Fig. 3a. This increased oxygen coincided with adding powder to the powder hopper, which occurred automatically. When the sample failure location is overlaid with these process data, one sees a loose correlation between the persistent failure location and the process upset. Additional analysis was conducted near the fracture location using SEM and EDS; however, the measurement sensitivity was insufficient to elucidate differences between the failure location and other areas in the sample.

The FT sample exhibited a crack in the outside wall with the more dramatic failure occurring internally. This sample was examined using digital 


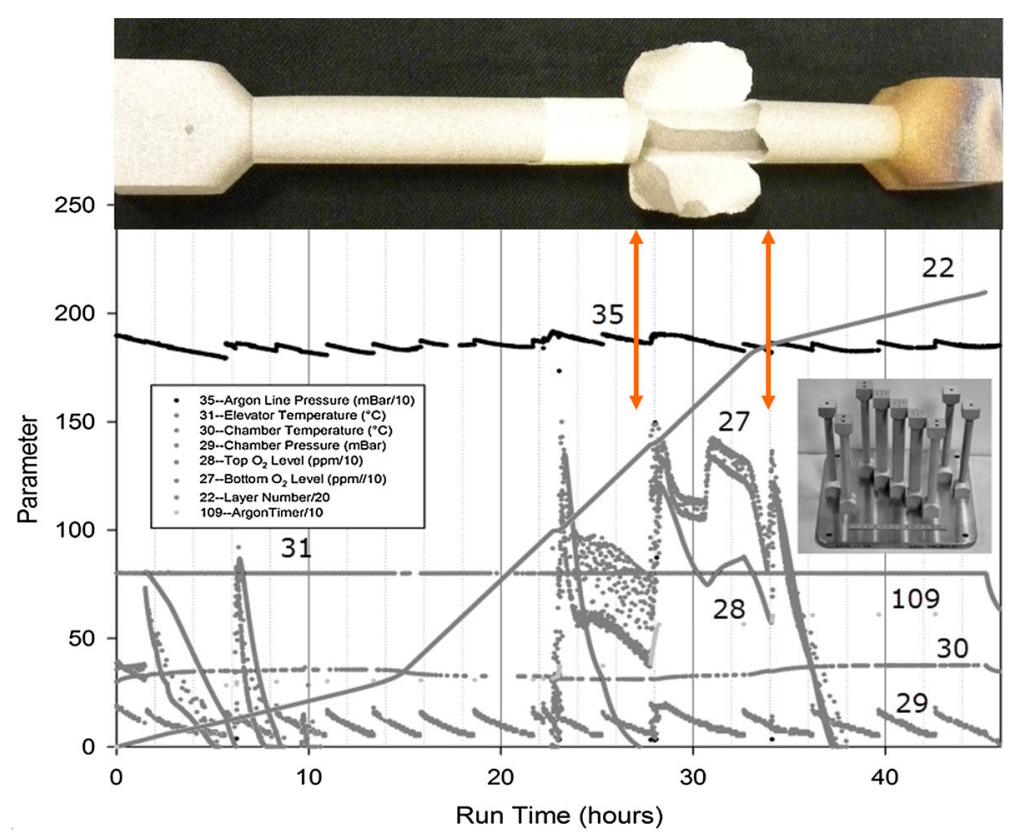

(a)

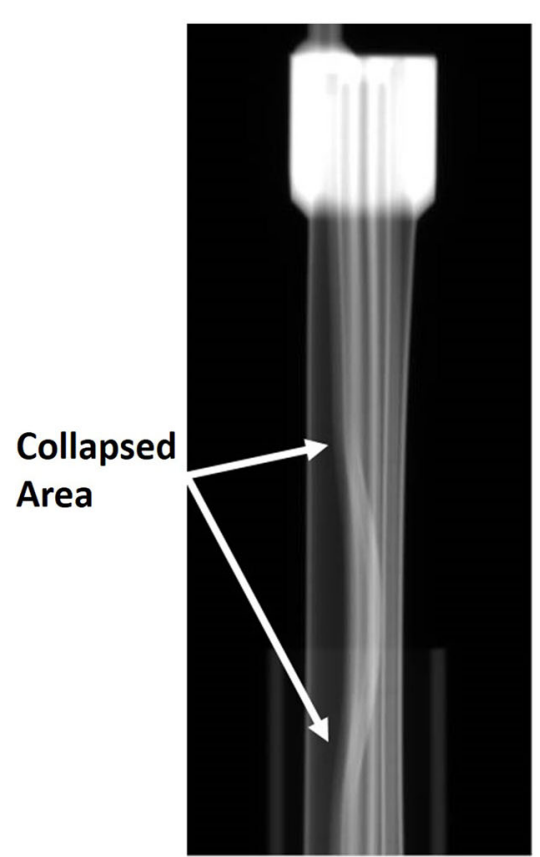

(b)

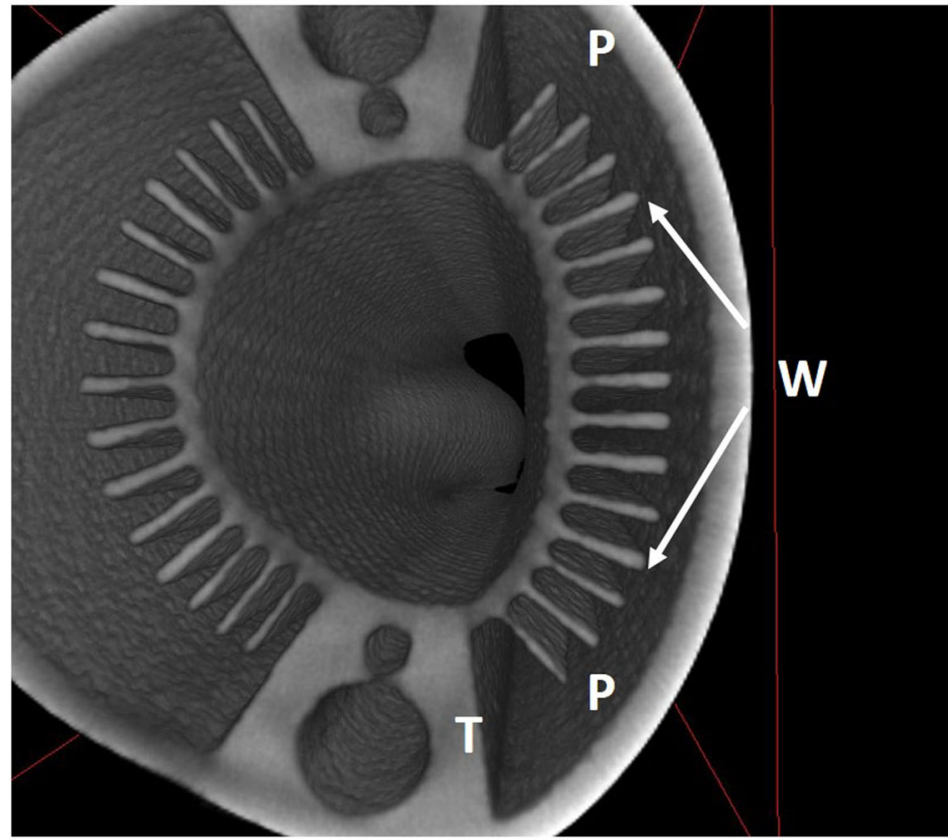

(c)

Fig. 3. (a) Process data from the Renishaw process controller overlaid with the DT burst sample. The process upset during about 23 to and $38 \mathrm{~h}$ was due to the automatic refilling of the recycle powder and coincides with the failure location of the burst samples. (b) X-ray image of the finned tube after burst testing and (c) three-dimensional reconstruction of the tube where $\mathrm{T}$ indicates the thermowell, $\mathrm{P}$ the poorly defined fin, and $\mathrm{W}$ the well-defined fins.

radiography and CT after failure. This examination revealed that the tube failed at the transition between the inner finned tube and the bulkier region for the heater coil. The tube collapse occurred locally in the same general build height as the ST and DT samples. Based on the CT and other posttest analyses, this location experienced a hinging effect and subsequent tearing. The static x-ray and a three-dimensional construction from the CT scan are shown in Fig. 3b and c, respectively. Figure 3c shows the bulging of the tube adjacent to the failure location on the left side of the image. The inner wall shows a significant amount of plastic deformation evidenced by the wave on the finned surfaces; it is 
not known if the deformation is due to the rapid pressure release on failure or if it is due to the pressurization. Another feature that is apparent from the CT is that the fins are not consistent in width and they appear to have voids and gaps. The quality of the fins varies with location with the fins closest to the bulky sections being thinner $(\mathrm{P})$ and less consistent than those near the center of the arc (W). Since these were first-of-a-kind articles, it is expected that additional builds can improve, if not eliminate, these discrepancies.

One sample from each of the segments was wire electrical discharge machined into metallographic samples and subsize (approximately $25 \mathrm{~mm}$ long $\times$ $1.5 \mathrm{~mm}$ wide $\times 1 \mathrm{~mm}$ thick) tensile test samples. The sectioned FT sample with tensile and metallographic specimens is shown in Fig. 4a; tensile test specimens were cut from the top and bottom sections. EDM relieved some of the fabrication strains, and the tubes spread as the samples were cut. As an example of the resultant strain relief, a second pair of tensile samples was cut at $90^{\circ}$ from the first, and these exhibited a width at one end of approximately $1.5 \mathrm{~mm}(0.06 \mathrm{in}$.) with a taper to about $0.7 \mathrm{~mm}(0.03 \mathrm{in}$.) at the other. The first pair of samples also exhibited $25 \mu \mathrm{m}$ to $50 \mu \mathrm{m}(0.001$ in. to $0.002 \mathrm{in}$.) of variation in the width, most likely due to stress relief during EDM.

Tensile testing of the samples from each tube type was conducted. The data from three test pieces, taken from the top of the tubes (the second " $T$ " in the sample type), are shown in Fig. $4 \mathrm{~b}$. These data indicate that the yield strength for these materials is consistent within each specimen type, but there were statistical differences between them. A comparison of the data using Student's $t$ test indicates that the yield strengths of the single tube (ST) and double tube (DT) and the DT and finned tube (FT) were statistically significant, but not between the ST and FT. ${ }^{20}$ Contrary to the results for the UTS, the only statistically significant difference was between the ST and FT samples. There was a fair amount of ductility as measured by the elongation; it too varied with the sample build geometry and was consistent with the yield strengths of ST and DT and of DT and FT, which were statistically significant, compared to ST and FT, which were not. Finally, a comparison of the RA and strain hardening data did not reveal statistically significant differences. The strain hardening data reveal interesting results, and unlike conventionally fabricated austenitic stainless steel, the AM tensile samples exhibit very little strain hardening. A comparison of the relative strain hardening of annealed stainless steel with this material suggests that the hardening coefficient is about $1 / 4$ of the annealed, i.e., annealed or forged austenitic SS has a strain-hardening exponent of about 12 versus the 3 that was observed in this study. A comparison of these data to annealed stainless steel and, more importantly, to a GTAW-welded stainless steel with nominal ferrite

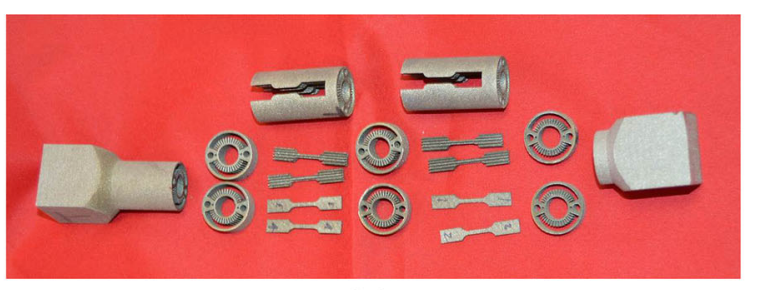

(a)

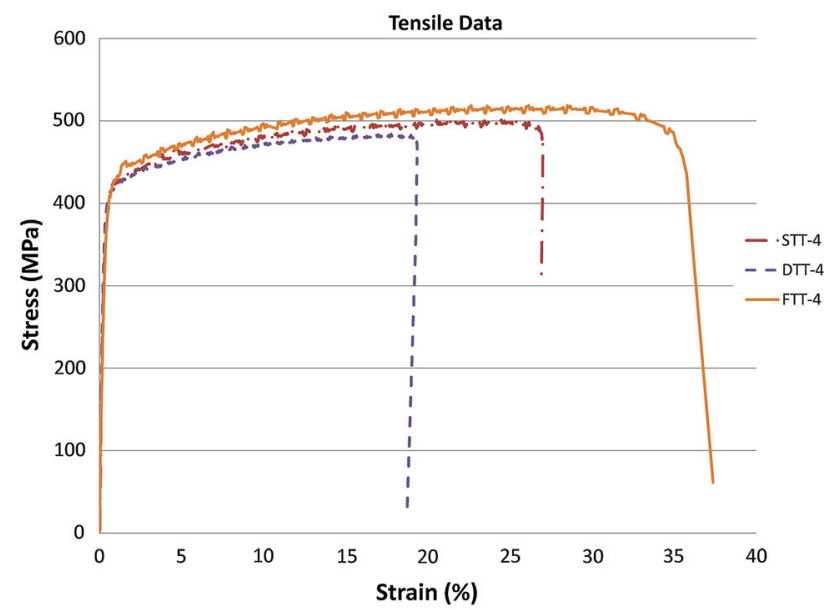

(b)

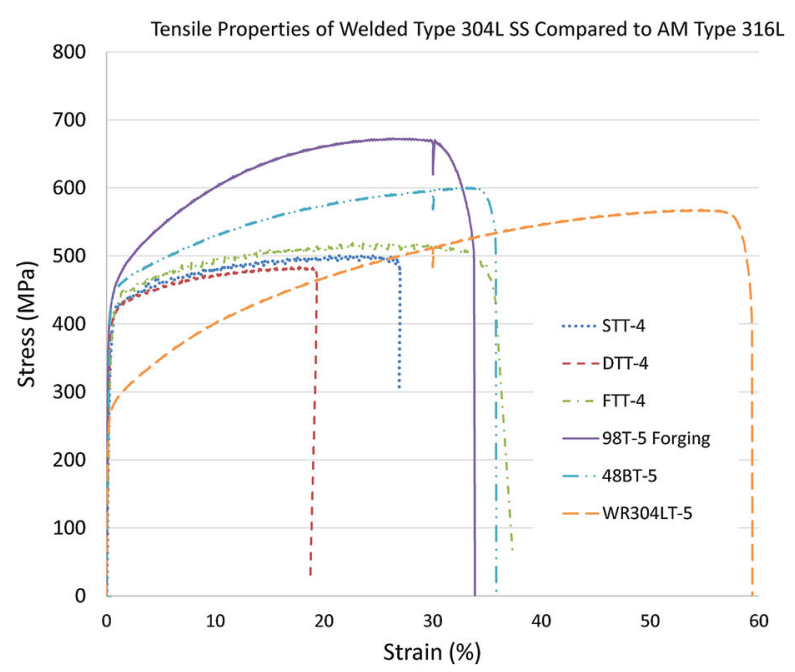

(c)

Fig. 4. (a) Configuration of test article EDM from the finned tube. The tensile samples on the left side were tested while the finned tensile shapes were not. (b) Tensile test data for one sample from each tube segment taken from the top of each tube: single tube (ST), dual tube (DT), and finned tube (FT). (c) Comparison of tensile test data for AM samples and weld samples; $98-5$ is type 309 SS welded with type 308 SS filler metal and 48BT is type 304L SS welded with type 308 SS filler metal and wrought type 304L SS and WR304LT-5.

contents, e.g., 304L with 308L filler wire, shows a higher strain hardening, as does the forged material (Fig. 4c). There is a reduction in the strain to failure, and the AM materials are consistent with the welded austenitic stainless steel. The salient 
data from the testing and the comparison data are listed in Table II. The relative strain-hardening coefficient was estimated by determining the slope of the engineering strain and stress after yielding. While this value is not an absolute value, it is a useful comparison and clearly shows that the strain-hardening characteristics of this material are different from those of forged 304L stainless steel and are similar to those of welded type 304L to type $308 \mathrm{~L}$ stainless steel. It is expected that the lower strain-hardening coefficient is related to the residual stresses, as indicated in other work, by the high dislocation density observed by other researchers. ${ }^{12,14,21,22}$

Fractography of the samples did not show any surface-related defects as the primary cause of failure. The samples generally exhibited ductile failure with fine cup and cone fracture features. There were regions of apparent brittle fracture, similar to quasi-cleavage, with a river pattern, but these were not extensively examined. The SEM images from the double-tube sample are shown in Fig. 5. These images are representative of all the fracture surfaces examined. The presence of pores on the fracture surface is evident but not patently obvious in these images, as reported by others as well. $^{23}$ There are some regularly shaped voids on the surface that may be indicative of partially bonded particles.

Figure 6 shows the metallographic cross sections for the FT sample, but all the tubes had metallographic samples cut from the bottom, middle, and top sections. These were examined in the axial and transverse orientations. Since all the samples were built at the same time, they all exhibited similar characteristics. The axial section for the top cut from the single tube is shown in Fig. $6 \mathrm{a}-\mathrm{c}$ and the transverse section in Fig. $6 \mathrm{~d}-\mathrm{f}$. The primary features are the absence of contour passes and the presence of partially melted particles on the surface. These adherent particles are common artifacts from the powder bed process. The samples also exhibit isolated pores. The porosity is scattered and appears as three distinct types. In one case it is spherically shaped, and these are likely due to gas pores that originate in the powder from the atomization process (GP), entrapped gas during laser melting, or laser keyhole $(\mathrm{KH})$ melting with relatively rapid solidification. Laser AM processes may require modification of the net energy input to minimize or eliminate the presence of KH porosity; however, the use of proprietary control software for the machines creates challenges for generating a robust process. $^{24,25}$ The other type of porosity is due to inadequate melting or lack of fusion (LF) and is interparticle porosity. ${ }^{26}$ These pores have sharp edges and somewhat regular shapes with sharp root radii, which may act as stress concentrators that affect ductility. The arrows highlight these types of pores and are due to lack of energy absorption. ${ }^{23}$

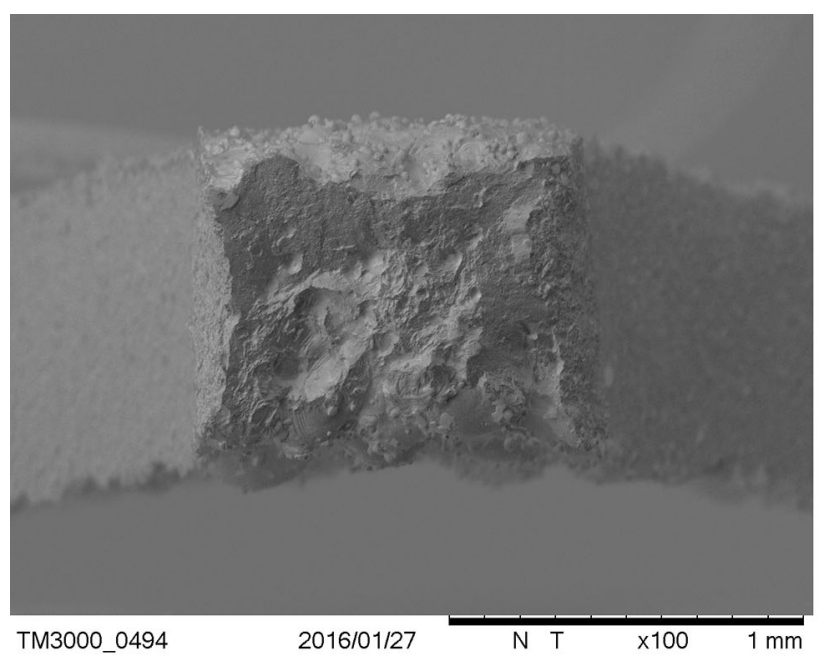

(a)

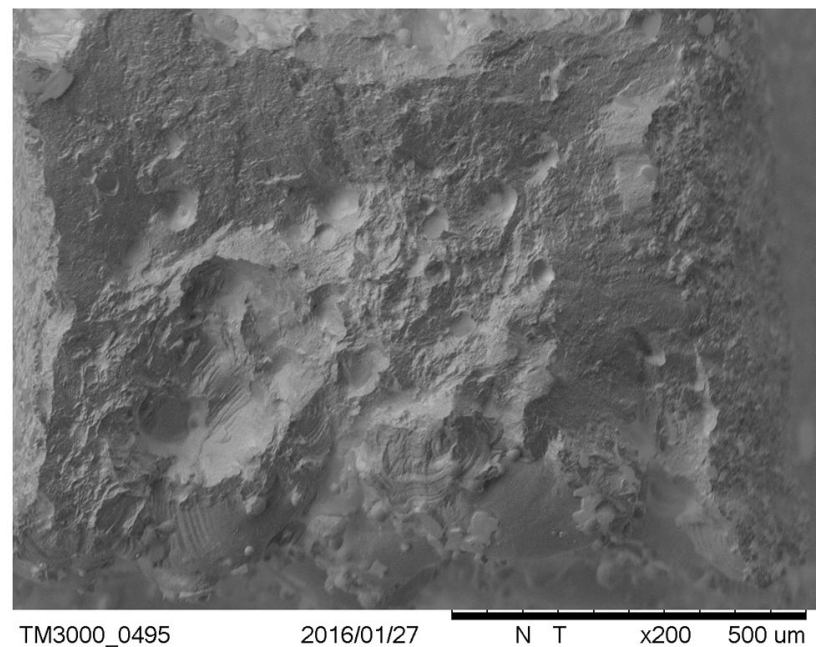

(b)

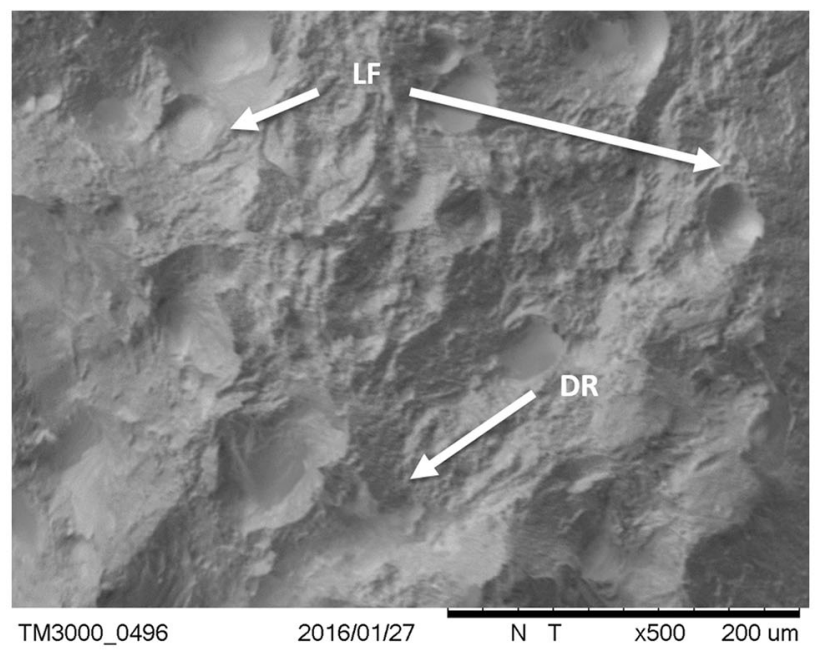

(c)

Fig. 5. Fractographic images of a tensile sample from the top of the double tube shown at (a) low, (b) medium, and (c) high magnifications exhibiting ductile rupture (DR) and some apparent lack of fusion (LF) defects. 


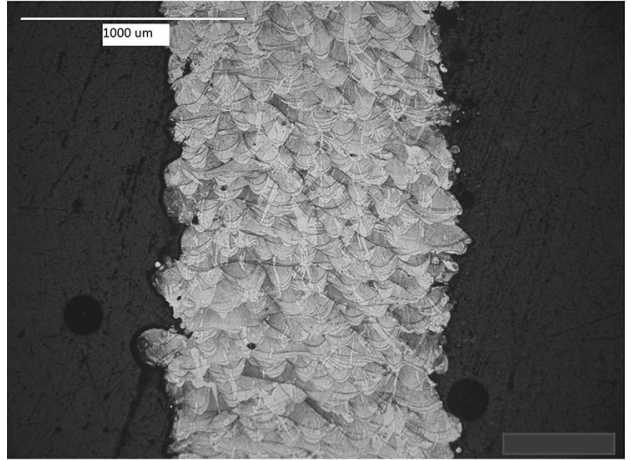

(a)

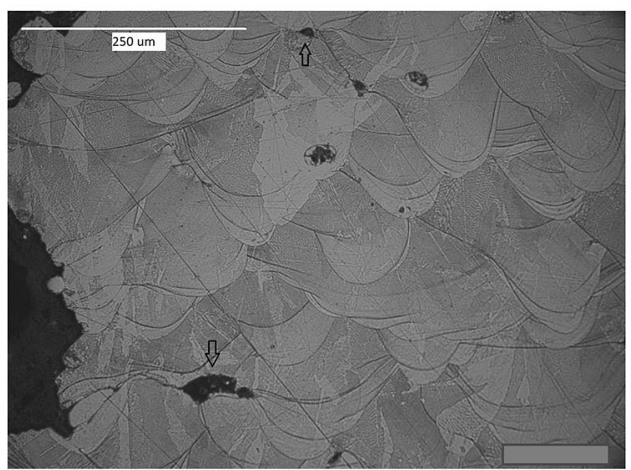

(c)

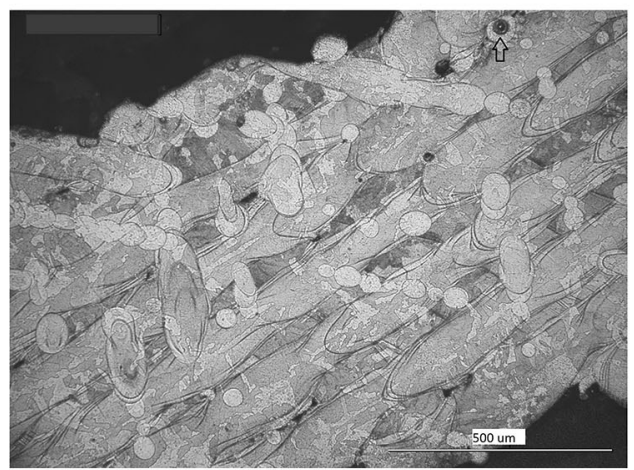

(e)

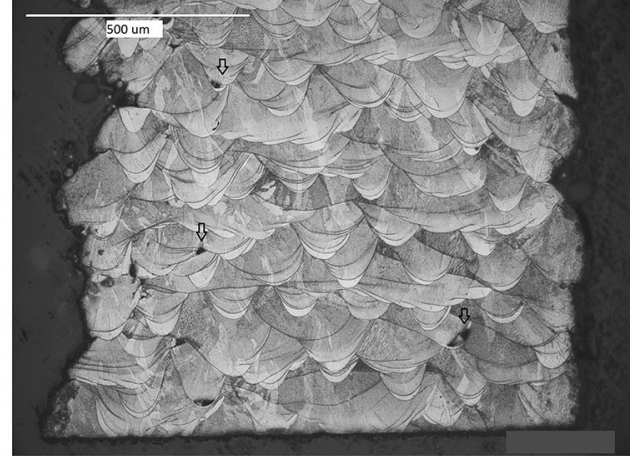

(b)

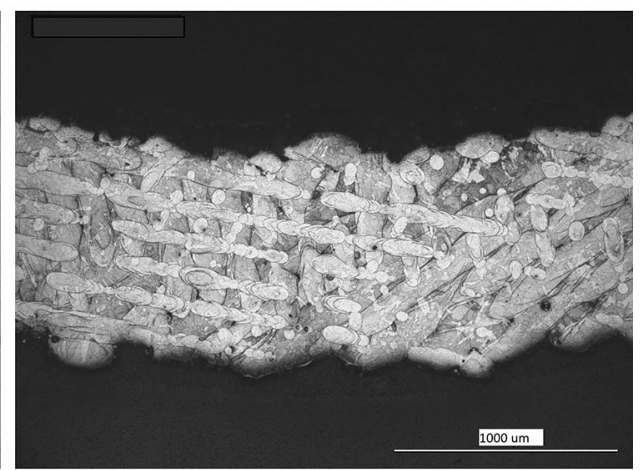

(d)

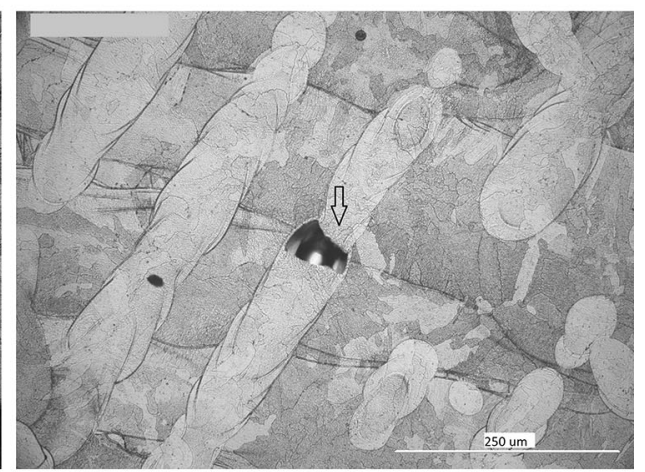

(f)

Fig. 6. (a-c) Metallographic cross sections of the single tube in the longitudinal orientation at increasing magnification. Arrow shows the lack of fusion (LF) pore; the build direction is up. (d-f) Metallographic cross sections of the single tube in the transverse orientation at three magnifications. (e) Arrows show keyhole (KF) and powder gas porosity (GP). Electrolytic $10 \%$ oxalic acid etch.

Grain growth is also apparent across the melt line interfaces. The grains have epitaxial growth lines, and some melt layers appear to be nearly continuous in the horizontal direction. These layers are consistent with the Renishaw laser control algorithm. The presence of the pores does not adversely affect the tensile strength of the tube or tensile samples. It does result in lower reduction of area and tensile elongation. Simple heat treatment ${ }^{16}$ did not eliminate the porosity, but it did reduce the tensile strength and recovered some of the ductility. Hot isostatic pressing would be required to close the porosity, but this treatment will also reduce the yield strength.

\section{SUMMARY AND CONCLUSION}

Several design concepts for process tubing were prepared for fabrication by selective laser melting at the MDF. These designs were refined and modified to make them more buildable. The modifications included angling edges to reduce overhangs and extending features to ports in the ends to facilitate powder removal.

Nine test elements containing three different internal geometries were fabricated. These test pieces were comprised of nearly 4200 layers. The external surface was somewhat rough, but there was no indication of surface-penetrating defects. 
Computed tomography did not show any defects in the as-built samples. CT of the finned tube sample indicated that the fins were variable in thickness and density with some voids and gaps.

Burst testing of the samples proved that the materials were of acceptable integrity. The finned sample had the lowest burst pressure and failed because of hinging near the thick to thin transition. The burst location coincided with a process upset that increased the oxygen content in the build volume.

Flat tensile test samples were wire electrical discharge machined from the tube test elements, and these materials provided favorable yield strengths, but the tensile strength and elongation to failure were lower than in the wrought material. In addition, the relative strain-hardening exponent for the AM was about one-third of the value for wrought material and even less than gas tungsten arc welded type 304L/308L SS; this is likely due to increased residual stress and potentially the presence of finely distributed delta ferrite interspersed in the austenite. ${ }^{14}$

The fracture surfaces exhibit ductile fracture with cups and cones; there is some evidence of preexisting pores on the fracture surface. The samples were not examined at sufficiently high magnification to determine whether there are inclusions associated with the dimples.

The metallographic examination shows the presence of two types of pores, gas pores and process pores. There is a low fraction of porosity in the samples that is composed of three sources, existing pores in the powder, lack of fusion defects, and keyhole laser pores. The samples exhibit an anisotropic microstructure with cross-hatching (basket weave) in the transverse orientation and a scalloped (fish-scale) appearance in the parallel orientation. Processing modifications are needed to eliminate the lack of fusion pores and to avoid the keyhole pores.

AM was shown to be a viable technology to fabricate process tubes that are short but with complex internal structures. The dimensions of the internal structures in the finned tubes were too small for the conditions used. The process parameters need to be modified to increase the density; these parameters include decreasing the hatch spacing, increasing the laser power, and modifying the scan strategy. The surface condition can also be modified by including contour scanning with the appropriate conditions to smooth the surface and avoid keyhole defects. ${ }^{27}$

\section{ACKNOWLEDGEMENTS}

This document and the research were prepared and conducted for the US Department of Energy under Contract Number DE-AC09-08SR22470 with Savannah River Nuclear Solution and with research sponsored by the US Department of Energy, Office of Energy Efficiency and Renewable Energy, Advanced Manufacturing Office, under Contract DEAC05-00OR22725 with UT-Battelle, LLC.

\section{AUTHORS' CONTRIBUTIONS}

The following individuals at SRNL and SRNS contributed to the success of this task by providing their expertise and support: Jacob Schaufler, Edward Stein, Tony Curtis, Lin Thacker, Ken Imrich, Kenneth Gibbs, Henry King, and Bob Snyder, and Keith Carver at ORNL MDF.

\section{REFERENCES}

1. L.E. Murr, S.M. Gaytan, D.A. Ramirez, E. Martinez, J. Hernandez, K.N. Amato, P.W. Shindo, F.R. Medina, and R.B. Wicker, J. Mater. Sci. Technol. 28, 1 (2012).

2. K.V. Wong and A. Hernandez, ISRN Mech. Eng. 2012. Article ID 208760.

3. S.S. Babu and R. Goodridge, Mater. Sci. Technol. 31, 881(2015).

4. D.D. Gu, W. Meiners, K. Wissenbach, and R. Poprawe, Int. Mater. Rev. 57, 133 (2012).

5. P.S. Korinko, in Proceedings of ASME 2015 PVP Boston, MA (2015).

6. B. Vayrea, F. Vignata, and F. Villeneuvea, in 45th CIRP Procedia CIRP, vol. 3 (2012), p. 632.

7. B.L. Boyce, Sandia National Laboratory, Albuquerque, NM, unpublished research (2016).

8. L.K. Heung, H.T. Sessions, and X. Xiao, US Patent 8470073 B2, (2013).

9. X. Xiao, H.T. Sessions, and L.K. Heung, Fusion Sci. Tech. 67,643 (2015).

10. L.K. Heung, H. Sessions, A. Poore, W. Jacobs, and C. Williams, Savannah River National Laboratory, Aiken, SC, unpublished research (2007).

11. L.K. Heung, G. Staack, J. Klein, and W. Jacobs, Savannah River National Laboratory, Aiken, SC, unpublished research (2007).

12. S.M. Thompson, Z.S. Aspin, N. Shamsaei, A. Elwany, and L. Bian, Addit. Manuf. 8, 12 (2015).

13. M.A. Arie, A.H. Shooshtari, and M.M. Ohadi, Appl. Therm. Eng. 129, 187 (2018).

14. Z. Sun, X. Tan, S.B. Tor, and W.Y. Yeong, Mater. Des. 104, 197 (2016).

15. G. Miranda, S. Faria, F. Bartolomeu, E. Pinto, S. Madeira, A. Mateus, P. Carreira, N. Alves, F.S. Silva, and O. Carvalho, Mater. Sci. Eng. A 657, 43 (2016).

16. P. Korinko and M. Morgan, in Proceedings of ASME PVP2018, Prague, Czech Republic (2018).

17. K. Antony, N. Arivazhagan, and K. Senthilkumaran, $J$. Man. Proc. 16, 345 (2014).

18. P. Korinko, J. Bobbitt, H. McKee, F. List III, and S.S. Babu, in Proceedings of TMS 2017 (2017).

19. D. Galicki and S.S. Babu, University of Tennessee-Knoxville, Knoxville, TN, unpublished research (2016).

20. Social Science Statistics, http://www.socscistatistics.com/te sts/studentttest/Default2.aspx. Accessed 10 Dec 2018.

21. D. Wang, C. Song, Y. Yang, and Y. Bai, Mater. Des. 100, 291 (2016).

22. J. Suryawanshi, K.G. Prashanth, and U. Ramamurty, Mater. Sci. Eng. A 696, 113 (2017).

23. R. Casati, J. Lemke, and M. Vedani, J. Mater. Sci. Technol. 32,738 (2016).

24. J. Zhou and H. Tsai, Trans. ASME 129, 1014 (2007).

25. B.C. Wood, T.A. Palmer, and J.W. Elmer, UCRL-ID-150357, OSTI, Washington, DC, September 2002.

26. B. Zhang, L. Dembinski, and C. Coddet, Mater. Sci. Eng. A 584, 21 (2013).

27. E. Yasa and J.-P. Kruth, Proc. Eng. 19, 389 (2011). 